\title{
Pyelonephritis Caused Solely by Escherichia hermanii
}

\author{
Yan Qing Tong ${ }^{1, *} ;$ Bing Xin $^{2}$; Shu Qing Sun ${ }^{2}$ \\ ${ }^{1}$ Department of Nephrology, The First Affiliated Hospital to Changchun University of Chinese Medicine, Changchun City, China \\ ${ }^{2}$ Department of Microbiology, The First Affiliated Hospital to Changchun University of Chinese Medicine, Changchun City, China \\ ${ }^{*}$ Corresponding author:Yan Qing Tong, Department of Nephrology, The First Affiliated Hospital to Changchun University of Chinese Medicine, Gongnong Road, No 1478, Changchun \\ City, Jilin province, China, P.O.Box:130021. Tel:+86-43186178717, Fax:+86-43186177222, E-mail: tongyanqing@yahoo.com \\ Received: February 15, 2014; Revised: March 2, 2014; Accepted: March 9, 2014
}

Introduction: In contrast with Escherichia coli, the association of E. hermanii with urinary tract infections has not been described. Case Presentation: In this case, E. hermanii was the sole isolate recovered from urine specimens of a pyelonephritis patient. The organism was found to be susceptible to piperacillin-tazobactam, ceftazidime, cefazolin, cefixime, aztreonam, gentamicin, tobramycin, imipenem, meropenem and amikacin, and resistant to amoxicillin. Antibiotic treatment was initiated with oral cefixime (400 mg every 24 hours). The symptoms were relieved within 72 hours after therapy. A urine sample was taken seven days after antibiotic therapy. E. hermanii was no longer isolated.

Discussion: The present case demonstrates that the uropathogenic E. hermanii clone can cause destruction of the kidneys. During asymptomatic bacteriuria or cystitis, the bacteria remain in the urinary tract. Even when pyelonephritis develops, inflammatory response of the host is still restricted to the urinary tract. These signs mean that uropathogenic E. hermanii may be not very virulent.

Keywords:Escherichia; Urinary Tract; Gram-Negative Bacterial Infections

\section{Introduction}

Pyelonephritis represents a renal injury induced by recurrent or persistent renal infection, associated with progressive renal scarring and may lead to end-stage renal disease (1). In 1982, Escherichia hermanii was classified as a distinct species within the Escherichia genus on the basis of DNA-DNA relatedness (2) and was considered to be nonpathogenic. In contrast to E. coli, the association of this organism with urinary tract infections has rarely been described. In this report, we described some of the uropathogenic properties of $E$. hermanii, which was clinically isolated from the urine of a pyelonephritis patient.

\section{Case Presentation}

A 65-year-old Asian female (Height: 5 feet 4 inches; Weight: $52.5 \mathrm{~kg}$; Occupation: retired teacher) referred to our clinic March 8th, 2013. Her family and social history was as follows; she lived alone and had quit cigarette smoking 10 years ago, with no alcohol or illicit drug use. Her mother had a history of colon cancer. She had a past medical history of a left breast mass that had required resection and radiation therapy. Three weeks before being admitted, the patient had presented an initial episode of cystitis. This was treated by a single dose of fosfomycin, which led to regression of the clinical symptoms. One day before hospitalization, she presented sudden onset of clinical signs of pyelonephritis: dysuria, urgency, frequency, urinary incontinence, suprapubic pain and elevated temperature $\left(37.7^{\circ} \mathrm{C}\right)$. Urinalysis revealed positive leukocyte esterase, with 50-60 white blood count and 18-22 red blood count per high-power field. Her serum creatinine level was $125.3 \mathrm{umol} / \mathrm{L}$ and hemoglobin level was $10.7 \mathrm{gr} / \mathrm{dL}$. There were no other significant laboratory findings.

Urine samples were taken and cultured using both Columbia blood agar (Acumedia Manufacturers, Inc., US.) and MacConkey agar (Teknova Inc., US.). Microscopic examination of Gram stained smears of the urine revealed Gram-negative rods. Yellow colonies of the microorganism were detected on all culture media after overnight incubation. No other bacteria were detected. The isolate was identified as E. hermanii after assessment using the API 20E system (bio-Merieux, Lyon, France) for biochemical properties and enzyme activities.

This isolate was forwarded to the local laboratory and biochemical testing and sequencing of the 16S rRNA gene confirmed the isolate as E. hermanii. The upstream primer used for the amplification of the $16 \mathrm{~S}$ region in the E. hermanii genome was 5'-AGAGTTTGATCCTGGCTCAG-3'. The downstream primer was 5'-ACGGCTACCTTGTTACGACTT-3'. The nucleotide sequence of the 16S rRNA gene amikacin. This case provides further evidence for the uropathogenic potential of E. hermanii.

Copyright (c) 2014, Ahvaz Jundishapur University of Medical Sciences; Published by Kowsar Corp. This is an open-access article distributed under the terms of the Creative Commons Attribution License, which permits unrestricted use, distribution, and reproduction in any medium, provided the original work is properly cited. 
was $99.86 \%$ identical to that of $E$. hermanii T91, according to the NCBI GenBank database. Bacterial cultures were grown aerobically at $37^{\circ} \mathrm{C}$ in an incubation chamber.

Antimicrobial susceptibility testing was performed using minimum inhibitory concentration (CLSI) broth microdilution minimum inhibitory concentration (MIC) method (3). The organism was found to be susceptible to piperacillin-tazobactam (MIC $\leq 4 \mathrm{mg} / \mathrm{L}$ ), ceftazidime (MIC $\leq 1 \mathrm{mg} / \mathrm{L}$ ), cefazolin (MIC $\leq 4 \mathrm{mg} / \mathrm{L}$ ), cefixime (MIC $\leq 0.25 \mathrm{mg} / \mathrm{L}$ ), aztreonam (MIC, $4 \mathrm{mg} / \mathrm{L}$ ), gentamicin (MIC $\leq 4 \mathrm{mg} / \mathrm{L}$ ), tobramycin (MIC $\leq 1 \mathrm{mg} / \mathrm{L}$ ), imipenem (MIC, $2 \mathrm{mg} / \mathrm{L}$ ), meropenem (MIC $\leq 0.25 \mathrm{mg} / \mathrm{L}$ ) andamikacin (MIC $\leq 1 \mathrm{mg} / \mathrm{L}$ ); and resistant to amoxicillin (MIC $\geq 16$ $\mathrm{mg} / \mathrm{L})$. Antibiotic treatment was initiated with oral cefixime (400 mg every 24 hours). The symptoms were relieved within 72 hours after therapy. A urine sample was taken seven days after antibiotic therapy. E. hermanii was no longer isolated.

\section{Discussion}

Pyelonephritis is a particular type of Urinary tract infection (UTI) that commonly originates in the urethra or bladder and travels up into kidneys. Pyelonephritis needs rapid medical care. If not treated accurately, the infection can permanently damage the kidneys or the bacteria can spread to the bloodstream and cause a lifethreatening infection. Pyelonephritis is a severe form of UTI with women being more likely to be affected than men. A wide variety of bacterial genera including enteric bacteria have been identified as putative pathogens. $E$. coli is involved in most UTI cases: $>80 \%$ of communityacquired UTIs and approximately $50 \%$ of UTIs in hospital patients (4).

Although other bacteria belong to the family Enterobacteriaceae, such as Proteus spp., and Klebsiella pneumoniae are occasionally isolated from the urinary tract, the association of $E$. hermanii with pyelonephritis has rarely been reported. Artero et al. (5) recently described E. hermanii isolated from the urine of a pregnant woman with pyelonephritis from the United States in a retrospective analysis of archived isolates. However, the origin of these strains was unclear and no clinical information was provided in the report.

E. hermanii is an extremely rare etiological agent for invasive infections. As a member of the family Enterobacteriaceae (6), E. hermanii is a Gram-negative rod-shaped bacterium commonly found in the wounds and feces of warm-blooded animals (2). In contrast to E. coli, E. hermanii can produce a yellow pigment and show various biochemical characteristics including the fermentation of cellobiose and a positive reaction to KCN (2). Unlike $E$. coli, this organism has not been detected in human genitourinary tract thus far. In this report, the organism was isolated from a urine specimen, which provides evidence that E. hermanii plays a role as an invasive pathogen in the urinary tract.

E. hermanii is primarily an opportunistic pathogen which causes disease in immunocompromised hosts (e.g. diabetes mellitus, malignancies, extremes of age) or in those who use a central catheter. It has been considered as an associated pathogen in a few invasive infections, which were mostly attributed to other coexisting bacteria that were more pathogenic $(7,8)$. In this case, $E$. hermanii was the sole pathogen recovered from a patient with pyelonephritis and was isolated in large numbers. However, its pathogenic role in this patient was uncertain.

It is very difficult to definitively comment on the treatment of E. hermanii UTIs. Findings and outcomes of the published data about the antimicrobial susceptibilities of clinical E. hermanii isolates are limited. However, in this case, E. hermanii isolates were susceptible to antimicrobial treatment. The in vitro susceptibilities of these isolates showed that piperacillin-tazobactam, ceftazidime, cefazolin, cefixime, aztreonam, gentamicin, tobramycin imipenem, meropenem, and amikacin were active in vitro. Isolates also showed a low-level resistance against amoxicillin, similar to that reported by Fitoussi et al. and Beauchef-Havard et al. $(9,10)$. However, more clinical experiments are mandatory. The mild clinical infection of our patient, allowed an oral regimen. We selected cefixime for its lowest MIC in vitro effectiveness against the pathogen.

The present case demonstrates that the uropathogenic E. hermanii clone can cause destruction of the kidneys. During asymptomatic bacteriuria or cystitis, the bacteria remain in the urinary tract. If insufficiently treated, the bacteria in the bladder will travel up into the kidneys. Even when pyelonephritis develops, the inflammatory response of the host is still restricted to the urinary tract. These signs mean that uropathogenic E. hermanii may not be very virulent.

In conclusion, the case of our study highlights the fact that E. hermanii may cause infection in the urinary tract as a sole pathogen. The case report we presented provides further evidence for the uropathogenic potential of $E$. hermanii, although much is still unclear about its pathogenicity.

\section{Acknowledgements}

We thank Hewei Wei for providing statistical advice and analysis.

\section{Authors' Contribution}

All authors in the article have contributed significantly and all authors are in agreement regarding the content of the manuscript.

\section{Financial Disclosure}

There is no conflict of interest. 


\section{Funding/Support}

This research was funded by the Natural Science Foundation of the Jilin Province (No. 201015207). The funding organization is a public institution and had no role in the design and conduct of the study, collection, management, and analysis of the data or preparation, review, and approval of the manuscript.

\section{References}

1. Roberts JA. Mechanisms of renal damage in chronic pyelonephritis (reflux nephropathy). Curr Top Pathol.1995;88:265-87.

2. Brenner DJ, Davis BR, Steigerwalt AG, Riddle CF, McWhorter AC, Allen SD, et al. Atypical biogroups of Escherichia coli found in clinical specimens and description of Escherichia hermannii sp. nov. J Clin Microbiol.1982;15(4):703-13.

3. Espinel-Ingroff A, Fothergill A, Ghannoum M, Manavathu E, Ostrosky-Zeichner L, Pfaller M, et al. Quality control and reference guidelines for CLSI broth microdilution susceptibility method (M 38-A document) for amphotericin B, itraconazole, posaconazole, and voriconazole. J Clin Microbiol. 2005;43(10):5243-6.
4. Chaniotaki S, Giakouppi P, Tzouvelekis LS, Panagiotakos D, Kozanitou M, Petrikkos G, et al. Quinolone resistance among Escherichia coli strains from community-acquired urinary tract infections in Greece. Clin Microbiol Infect. 2004;10(1):75-8.

5. Artero A, Alberola J, Eiros JM, Nogueira JM, Cano A. Pyelonephritis in pregnancy. How adequate is empirical treatment? Rev Esp Quimioter. 2013;26(1):30-3.

6. Pien FD, Shrum S, Swenson JM, Hill BC, Thornsberry C, Farmer JJ, 3rd. Colonization of human wounds by Escherichia vulneris and Escherichia hermannii. JClin Microbiol. 1985;22(2):283-5.

7. de Baere T, Wauters G, Huylenbroeck A, Claeys G, Peleman R, Verschraegen $\mathrm{G}$, et al. Isolations of Leclercia adecarboxylata from a patient with a chronically inflamed gallbladder and from a patient with sepsis without focus.JClin Microbiol. 2001;39(4):1674-5.

8. Popescu GA, Daha I, Popescu C, Mitache E. Staphylococcus aureus and Escherichia hermanii in diabetes patient. Emerg Infect Dis. 2004;10(7):1335-7.

9. Fitoussi F, Arlet G, Grimont PA, Lagrange P, Philippon A. Escherichia hermannii: susceptibility pattern to beta-lactams and production of beta-lactamase. J Antimicrob Chemother. 1995;36(3):537-43.

10. Beauchef-Havard A, Arlet G, Gautier V, Labia R, Grimont P, Philippon A. Molecular and biochemical characterization of a novel class A beta-lactamase (HER-1) from Escherichia hermannii. Antimicrob Agents Chemother. 2003;47(8):2669-73. 